\title{
Distinctive Features of the Composition of Damascus Buildings During the Period of the French Mandate
}

\author{
Hiba Abass ${ }^{1, *}$ \\ ${ }^{I}$ Department of Theory and History of Architecture, Damascus University, Faculty of Architecture, Damascus, \\ Syria \\ *Corresponding author. Email: arch.hebaabbas@hotmail.com
}

\begin{abstract}
The article is devoted to study the features of the volumetric compositional organization of the buildings in Damascus during the French Mandate; the author determined the architectural-artistic image of the buildings in Damascus during that period. A comparative study of the architectural elements of the facades of buildings in the city of Damascus during the French Mandate and the identification of Western architectural influences on traditional architecture was carried out. The residential and public buildings built during the French Mandate and located on the main streets and squares of Damascus can be classified according to the adopted type of compositional solutions, and each of which has analogs in the architecture of France (more broadly, Europe) of the second half of the 19th - early 20th centuries. The purpose of this article is to study and analyze the features of the composition of the buildings in Damascus during the period of the French Mandate, to determine the nature of the influence of European architecture on local architecture.
\end{abstract}

Keywords: Damascus, The French Mandate, European architecture, Public buildings, Residential buildings.

\section{INTRODUCTION}

At the beginning of the twentieth century, the synthesis of architecture from different countries becomes a growing directions among Syrian and European architects, during the French Mandate period, which was from 1920 till 1946, the culmination of the Westernization of Syrian architecture revealed the contradiction between the modern and traditional architecture. At the same time, the Western-style of buildings is becoming an inexhaustible source of ideological and artistic inspiration, and the West is becoming a theoretical guide and a source of necessary technical knowledge. European architects and the Syrian architects, who learned in Europe, was reflected the means that turned Westernization into a "Radicalization" movement. Thus, at the time of the French Mandate, the architectural and construction practice of Damascus was divided into Western and local directions. Each has its own pioneers, its own styles, and its own intellectual foundations. The main prerequisites for the spread of European trends in the architecture of Damascus during the
French Mandate were- Changes in legislation, political factors, economic factors, social factors, administrative aspects, religious and cultural factors, transport and planning.

\section{COMPOSITIONAL VOLUMES OF BUILDINGS FACADES DURING THE FRENCH MANDATE}

In 1936 in accordance with Article 1 of the Decision of the High Commissioner of France No. 6 dated 10/1/1936, the Damascus Municipality and the local administration were established, in which the development of architectural activities and the identification of regulating documents of architecture and construction began. A large number of provisions were devoted to the formation of the architectural and artistic image of Damascus buildings, corresponding to European standards.

In accordance with these documents, requirements for the architectural solution of facades were formed and standards for spatial planning and decorative solutions for buildings were established. The height of the building was set 
according to the width of the street and the maximum height of the building in Damascus (17 $\mathrm{m}$ ), since the height of the first floor of the building was (at least $4.5 \mathrm{~m}$ for shops), the characteristics of the decorative elements were determined (the height of the decorative elements - from 15 to 40 $\mathrm{cm})$.

In places marked by a certain prevailing architectural style, new buildings must conform to the prevailing style. The type of facade cladding was also determined, taking into account the influence of natural conditions and the aesthetic qualities of the material, as well as the characteristics of the building. [1].

The compositional volumes of the facades were as follows:

- Strongly protruding with central risalit (An avant-corps), towering over the crowning cornice. Risalit was a popular solution in Damascus architecture during the French Mandate. In fact, the risalit is a decorative part of the facade that protrudes beyond the main part of the building and runs along its entire length. Risalits are attached to the central part, gave the facade of the building an exquisite and unique appearance, and located along the entire height of the building.

In most cases, this façade element is flat in order to maintain the shape of the building.

Risalit in architecture is, first of all, the elegance and completeness of the structure of the facade of the building. (For example, Water Management Corporation, Al-Nasser St., No. 1370.)

- Symmetrical facade. The most famous types of symmetry in Damascus buildings during the French Mandate are reflective or mirror symmetry, where repetition occurs across a hypothetical straight line, the axis of reflection, and creates a mirror image. This type of symmetry plays an important role in all cultures, and it is well known that this type of symmetry is the most common in architecture. (For example, Ministry of health, Halboni St., No. 1100.).

- Asymmetrical facade. At that time, asymmetric buildings were rarely found in Damascus, because the aesthetic standards in the architecture of the city of that time considered the symmetry of the facades to be one of the most important elements of the city's urban image. (For example, Commercial bank, Al-Jemhuria St., No. 1031.).

- Symmetrical facade, the roof of the main entrance is sloping in two directions and covered with brick material. The influences surrounding the architecture of the French Mandate period can be extrapolated through the appearance of sloping and gabled roofs, which were not previously available due to the nature of the environment in Damascus and the lack of the need for such roofs. (For example, Presidency of Damascus University, Musalam-Al Baroudi St., No. 1160).

- Flat facade without protruding blocks, with internal stairs. Several buildings appeared with flat facades without any architectural protrusions or balconies, imitating some buildings that appeared in France at that time. (For example, Department of Agriculture, St. Al Nasser, No. 1290.) ("Table 1") [2]

Table 1. Facade composition influence of Western European architecture Damascus buildings during the period of the French Mandate "1920-1946."

\begin{tabular}{|l|l|l|l|}
\hline & Facade composition scheme & Analogues from French architecture & $\begin{array}{l}\text { Examples of facades of buildings in } \\
\text { Damascus }\end{array}$ \\
\cline { 3 - 5 } & & &
\end{tabular}




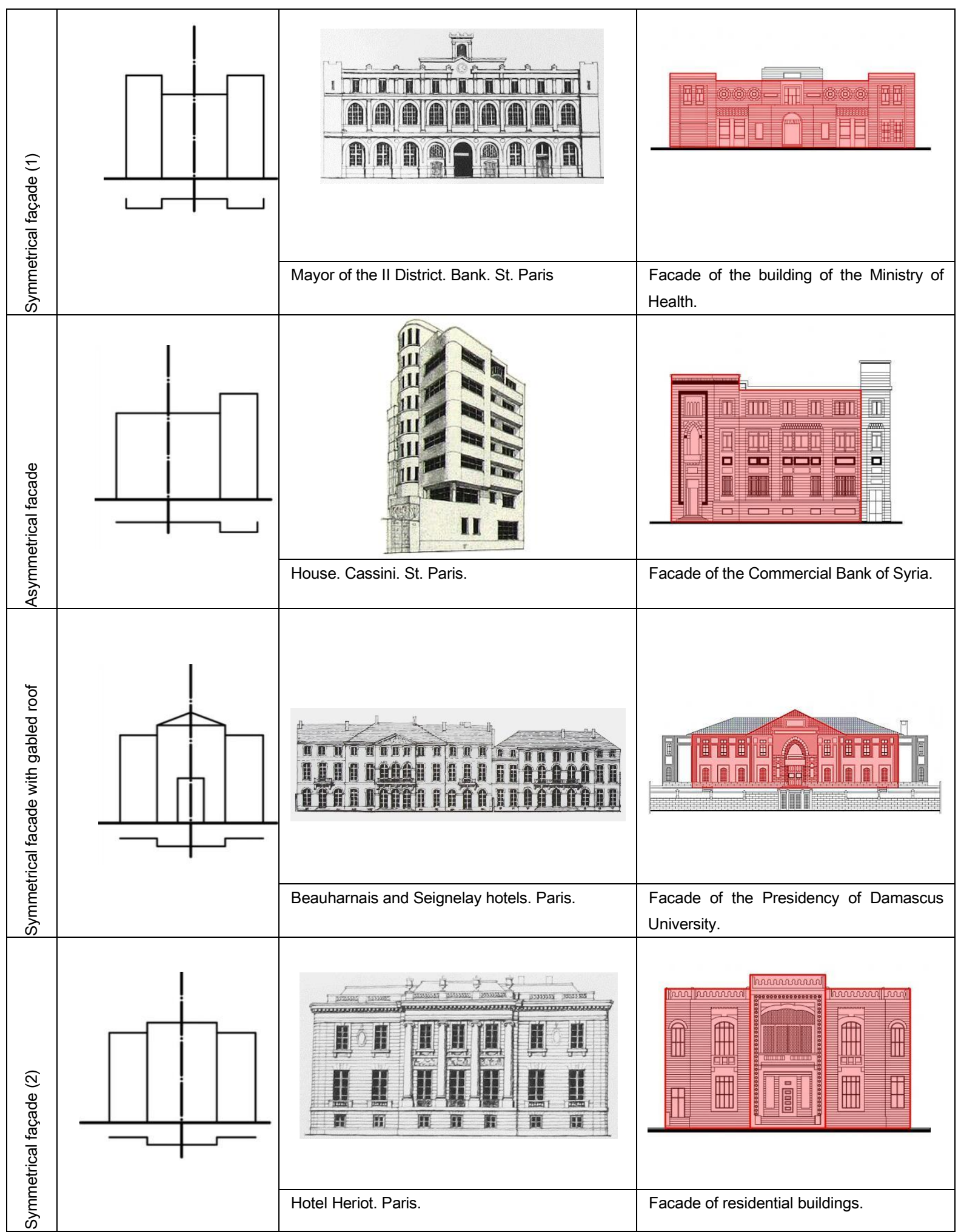




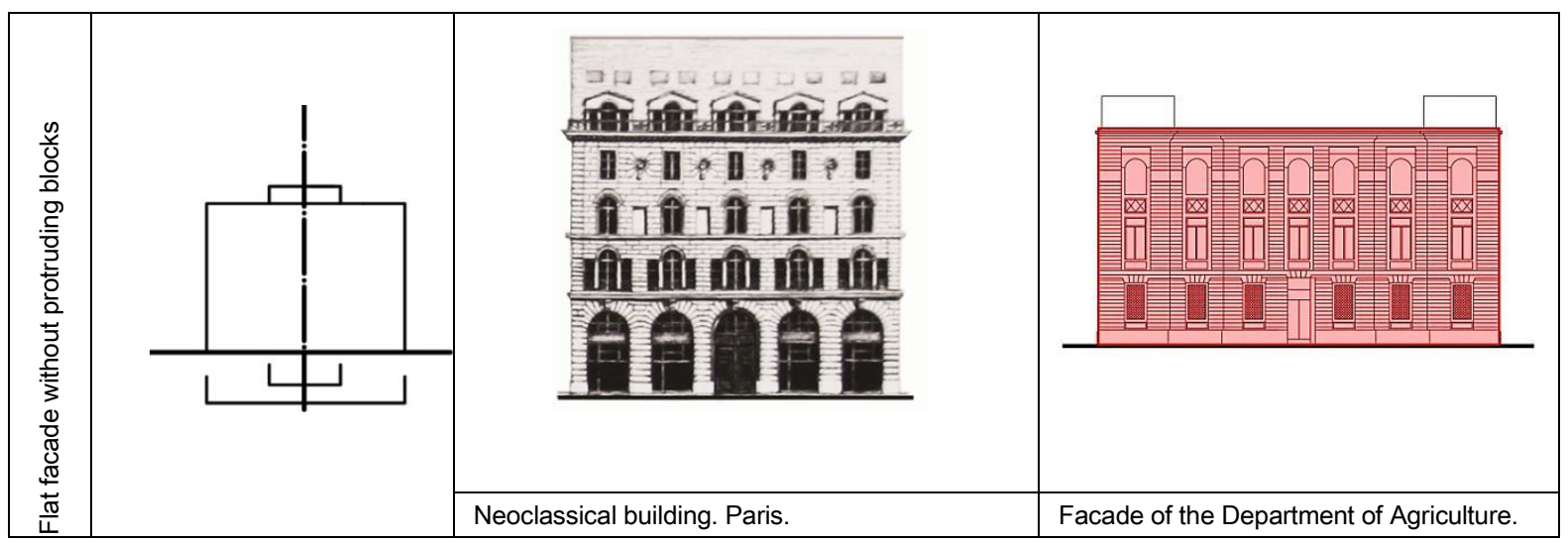

\section{COMPOSITIONAL VOLUMES OF BUILDINGS PLANS DURING THE FRENCH MANDATE}

The space-planning structure of a building is a system of combining the main and auxiliary rooms of selected sizes and shapes into a single integral composition. On the basis of the location and interconnection of the premises, several basic space-planning systems of buildings are distinguished. In order to properly organize the interior of a building, it is important to choose the most suitable compositional scheme.

In this case, the designer is required to determine which of them will be the most optimal in order to use all the internal volumes of the structure in accordance with their functional purpose.

The main characteristic feature of the corridor layout scheme is that during its implementation, all rooms are located on two, one or partly one, and partly two sides of a common corridor, which is connected by one or more staircases. Can be divided into - a scheme with a central corridor (For example, Al-Sharq Hotel, Hejaz Square, No. 1162.), - a scheme with a one-way corridor (For example, Al-Layik School, Baghdad St.), a central and oneway corridor (For example, Franciscan school, AlBarlaman St., No. 1154), and a diagram with the surrounding corridors (For example, the Department of Agriculture, Bakhsa St., No. 1290.). [3].

If the rooms are located on both sides of the corridor, then to ensure its natural light in the end walls, windows are equipped. As for the length of common corridors, in buildings designed according to the corridor scheme, it is 20 meters when illuminated from one side and 40 meters when illuminated from two sides.

In cases where, in addition to natural lighting from the ends, additional lighting is provided in common corridors with the help of light gaps (that is, expansion of the corridors), then the distance between these light gaps should not be more than 20 meters. As for the distance between the window and the light openings at the end of the corridor, it should not exceed 30 meters. [4].

- Compact layout - The main distinguishing feature of the centric compact layout is that its "core" is the main room, which is large enough. Around it are grouped utility rooms, which have a much smaller area. (For example, the Ministry of Technologies and Communications, Parlamentskaya St., No. 1059.).

- Courtyard - The courtyard system is based on the subordination of a relatively small number of utility rooms to the courtyard, which determines the functional purpose of the building as a whole. The most common courtyard system in the design of schools, hospitals, etc. The hall system is used for buildings with one or more halls. (For example, Danish Hospital, Al-Nabek St., No. 219.).

- The courtyard system, replacing the recreational hall, is a building with an open or covered courtyard, around which the main premises are located, opening directly to the courtyard through open or closed side corridors. (For example, Al-Tajhiz Alula School, Al-Mutanabbi St.).

- The Pavilion type scheme is based on the fact that all premises located in the constructed ones are grouped into groups of the same layout, called sections, connected by open or closed corridors and 
surrounded by gardens. (For example, French Hospital, Cassaa St., 269.).

In the practice of building design, sometimes more complex schemes are used called "Block type", which are various combinations of the above.

Table 2. Plans composition influence of Western European architecture Damascus public buildings during the

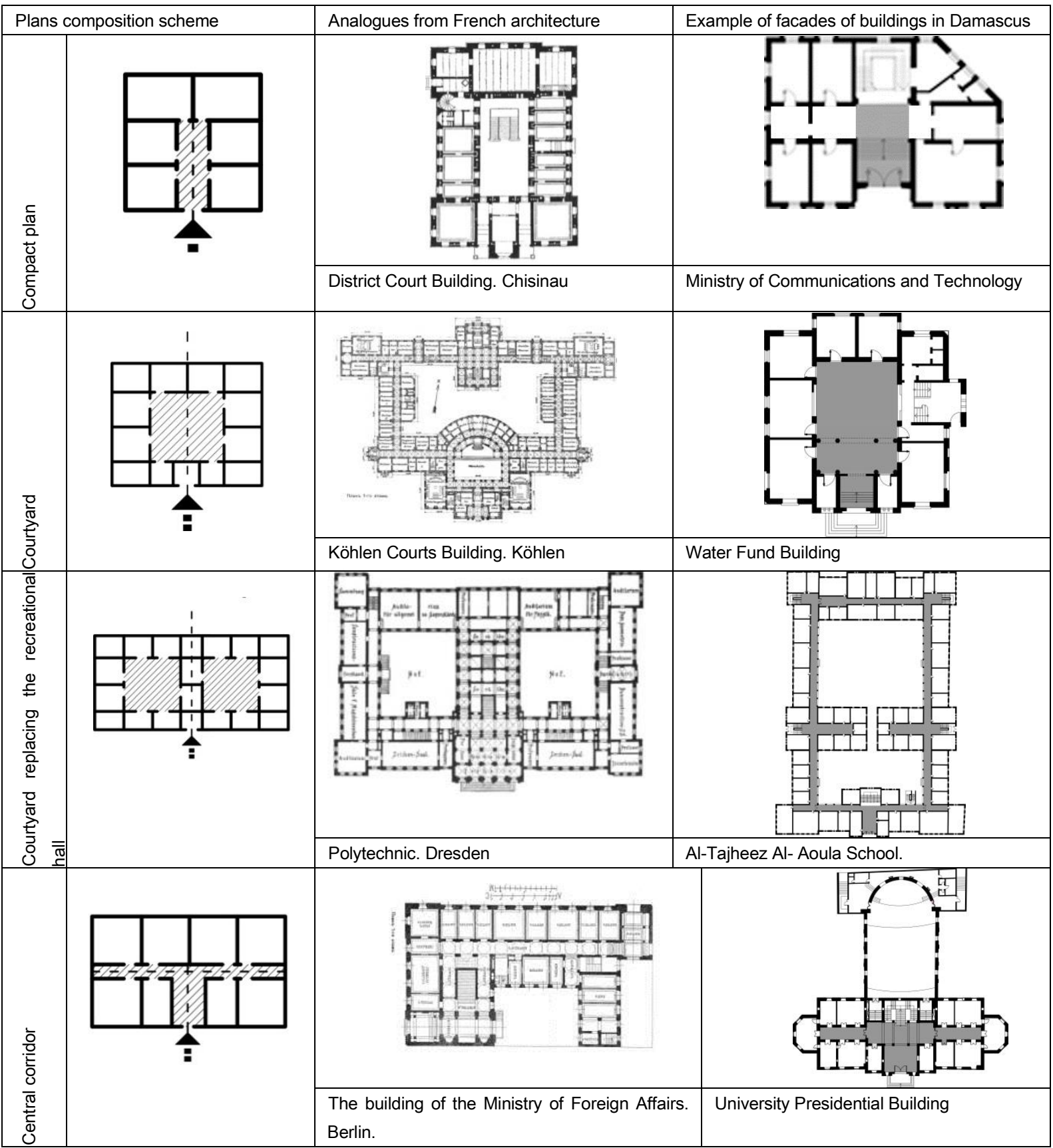

Most often, it consists of many blocks in one building layout, interconnected by internal Abdulnasser St., 193.) ("Table 2") [5] corridors. (For example, Italian Hospital, Jamal

\section{period of the French Mandate "1920-1946."}




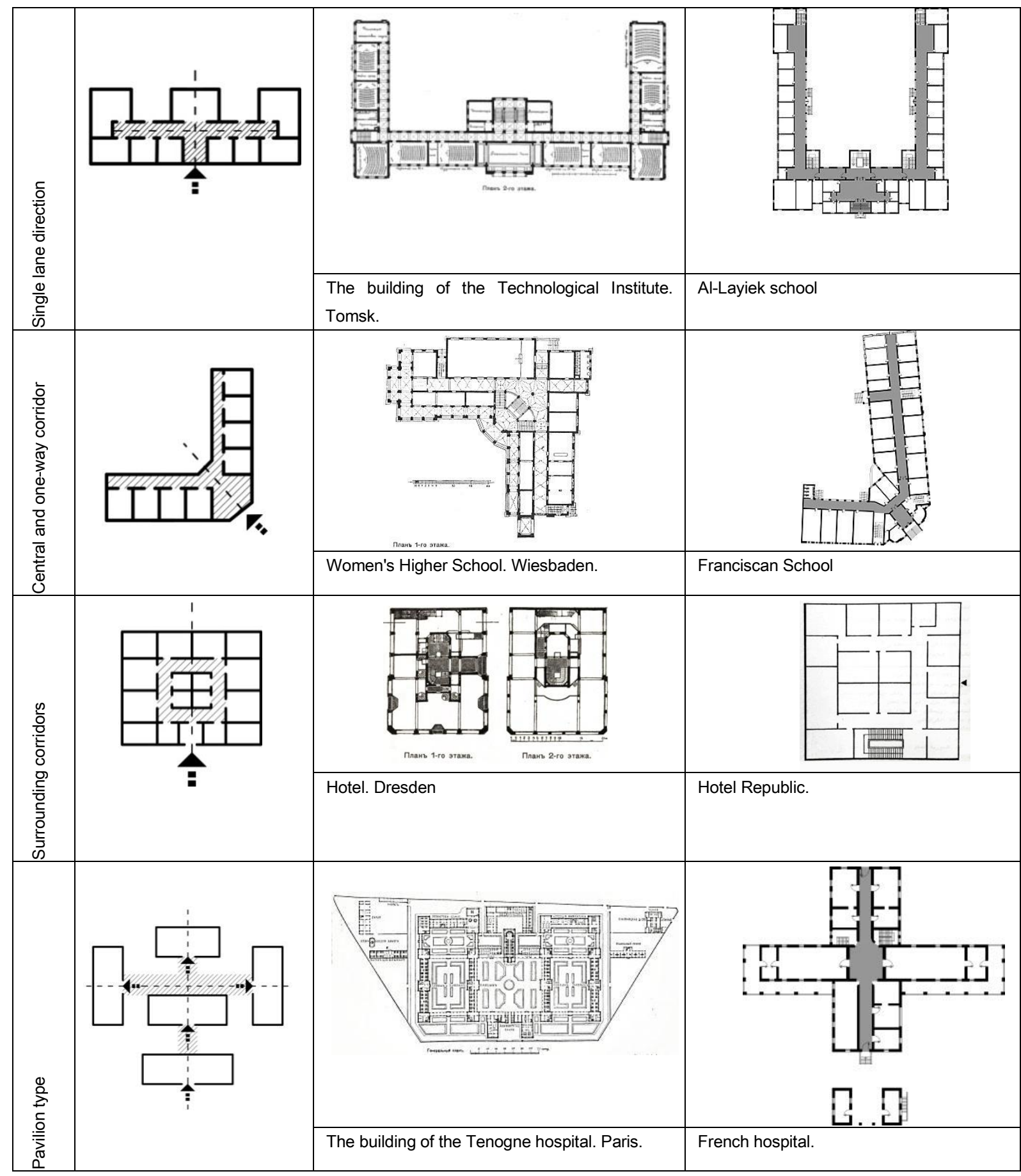

Analyzing the functional relationships of residential buildings, it was noted that in most projections there is a common element, which is "sofa or salon", which represent the largest spaces of the homes, often occupying the middle position in the architectural plan and the distribution of rooms. Based on this, plans can be divided into four models: [6].
- Interior space (sofa) with surrounding rooms - In this case, the salon is entered directly. The salon plays the role of a large area surrounded by rooms, from which it is moved to a corridor that leads to the kitchen, bathroom and toilet.

- Entrance leading to the inner space (sofa) with surrounding rooms - This case differs from the previous one in that the entrance to the house is not carried out directly into 
the salon, but to a small distributor, which leads from one side to the services, and from the other side to the salon, and from it to the rest of the rooms of the house.

- Corridor leading to the inner space (sofa) with surrounding rooms - The entry is made into a corridor that leads to the rest of the rooms of the house including the salon, which occupies a side position.
- Inner space (sofa) connects to two corridors with surrounding rooms - In this case, the salon is located in the center, in the middle of two opposite side corridors relative to the salon, and then it is distributed among the rest of the rooms and services of the house, which reduces the dominant role (sofa), and the entrance to the house is either directly to the salon or to one of the corridors, which distributed between rooms and services. ("Table 3") [7]

Table 3. Plans composition influence of Western European architecture Damascus residential buildings during the period of the French Mandate "1920-1946."

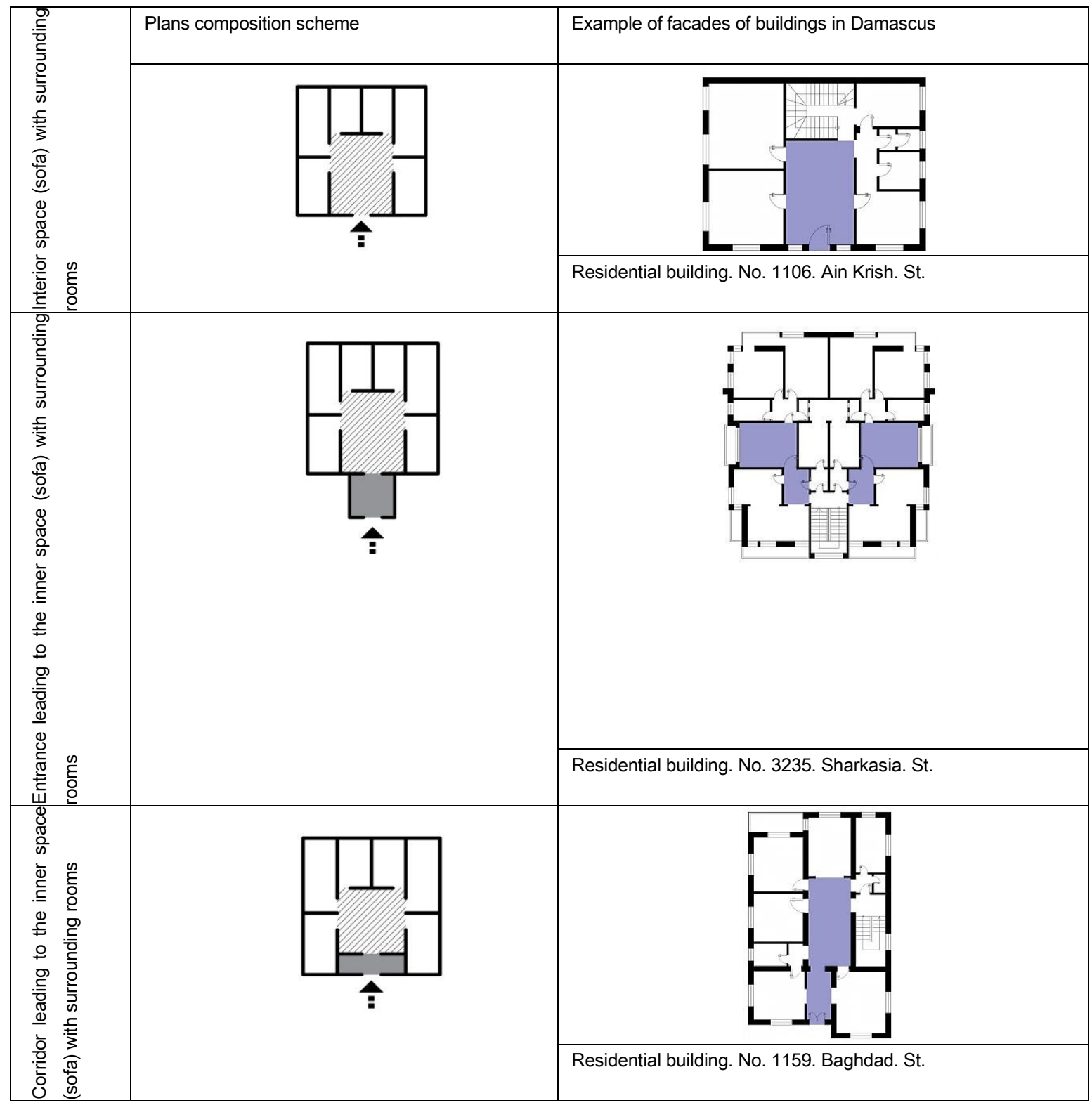




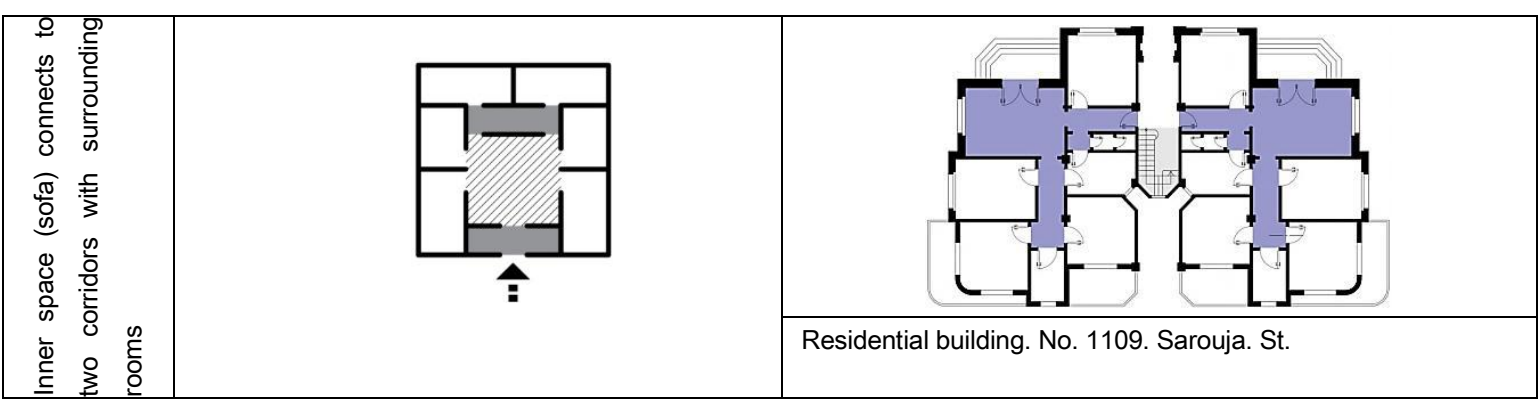

\section{AN ANALYSIS OF A MODEL OF BUILDINGS IN DAMASCUS DURING THE FRENCH MANDATE}

Analysis of the architectural plan of the Water Corporation - The shape of the scheme is square, the architect used a geometric grid (module), which was divided into 16 modules, administrative spaces were distributed between them. The square plan was divided into four modules along the $\mathrm{X}$-axis and three and a half modules along the $\mathrm{Y}$-axis, that is, the width of the plan along the $\mathrm{X}$-axis $(\mathrm{A} 1=4 \mathrm{~B})$ and the length of the plan along the $\mathrm{Y}$-axis $(\mathrm{A} 2=$ $3.5 \mathrm{~B})$.

The proportion of the courtyard and the surrounding corridor was about $1 / 2$ of the plan width, while the entrance occupied $1 / 3$ of the total space of the plan and separated it from the main hall by a series of decorative circular columns, some of the surrounding rooms took up $1 / 4$ of the length of the plan, the rest took up 3/4 of the width of the plan, which is equivalent to one and a half module, as for the main spaces, their share is $1 / 2$ of the total plan width. Equivalent to two modules, such as the main hall on the second floor, we find that the architect relied on a particular module in the design of the building, which is indicated by the symbol (B).

The architect has created a single and dominant element in the plan - A square courtyard in the center of the scheme, around which the interior spaces were arranged, which gave the plan clarity and complete balance and created a relationship between the staircase and the courtyard, placing the staircase on the axis of the courtyard in order to achieve a vertical relationship between floors and its direct openness to it.

The movement in the area took on a special character compared to other public buildings due to the presence of a courtyard, which gave central importance to movement, and the entrance also stood out from the rest of the spaces. The architect chose a central movement that starts at a point and spreads around a circle, and then ends at the same point.

In the volumetric-spatial composition, there is a central-axial symmetry, in which the main entrance was located in the area of the central block, while only window openings were located on the surrounding parts.

Golden Ratio - like all aesthetic relationships, its use in design provides a certain degree of orderliness and consistency of the project, which is important in architecture, because a building is rarely perceived from one distance.

Noticeably, the golden ratio has been applied to many of the compositional elements of a building, including layout, spacing, content, and shapes. The Golden Ratio is a useful guideline for determining the size of a building.

Analysis of the facade - The facade is designed according to the principle of absolute symmetry and axial orientation of all architectural elements that make up the facade, A noticeable reflection of the module of the adopted plan on the facade, which is Module (B) and its smaller parts (B/2, B/3, B/4) That gave a sense of harmony, integrity and aesthetics of the architectural facade of the building, the width of the facade is four modules (4B) and the height is three modules (3B).

The vertical division of the facade of the building prevailed over the horizontal division in order to create the feeling that the facade is higher than reality; this was embodied by the retraction on the surface of the facade and framed by decorative protrusions that unite the windows of the first and second floors.

The horizontal partition was not completely absent from the facade, but was in harmony with the continuous stone layer and with the outer window sill and the lintels of the rectangular windows. [8]. 
The analyzing of the compositional structure of the facade, it was noticed that its individual parts in their sizes and ratios correspond to the so-called law of Polycleitus, that is, to the "square" system of proportions; the facade was built on the principle of a square and a rectangle.

The middle part of the facade (first and second floors) also forms a rectangle, the base of which is equal to the diagonal of a square with a side equal to the height of the rectangle. Stone decorative inserts under the windows of the second floor of the central part of the facade also form squares.

The building is clear and understandable in its materialization and proportions. The golden ratio was used for the ratio of length and width, as the main proportional system and the main module for defining windows in relation to the entire facade and for determining the dimensions of the window itself.

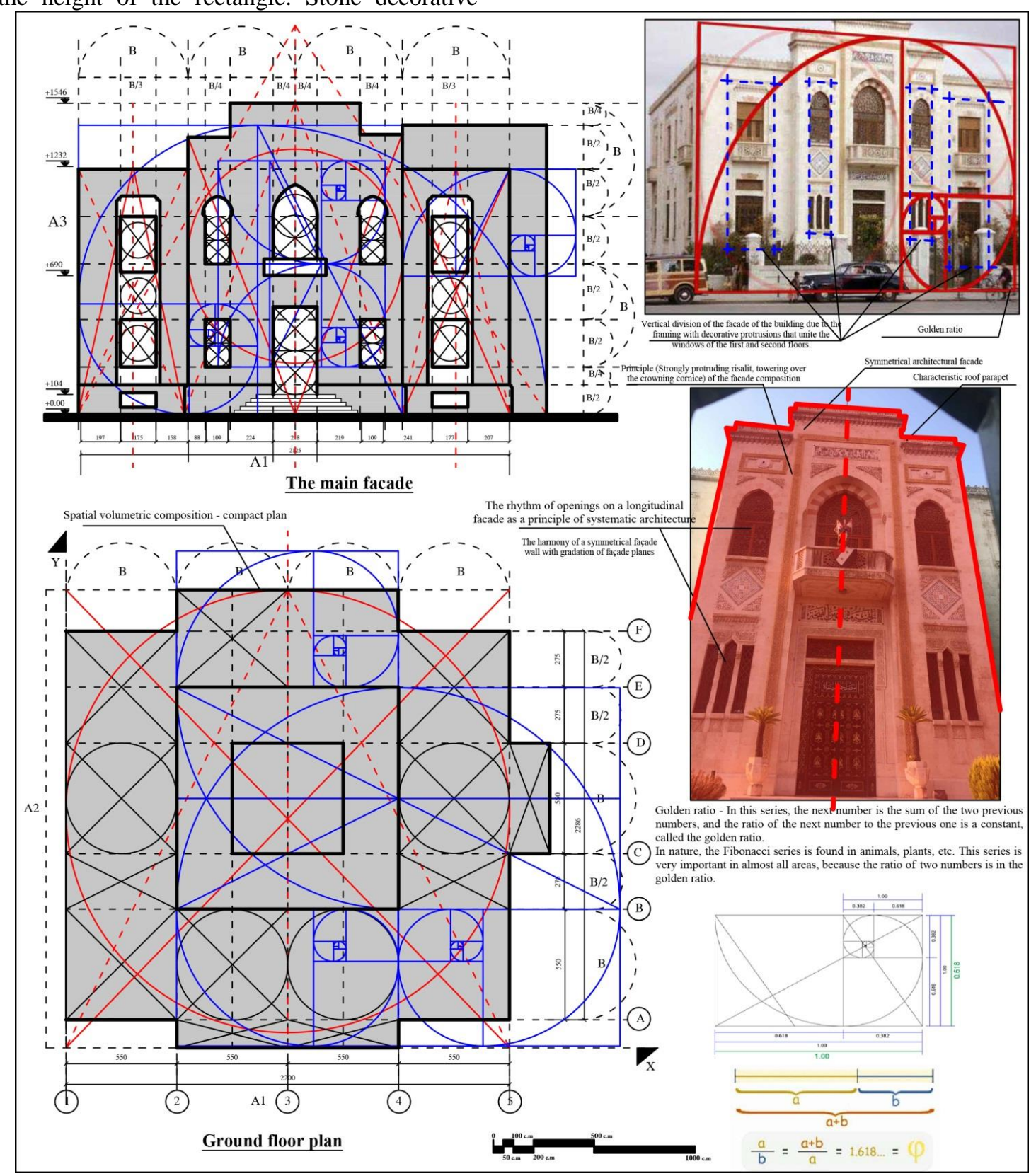

Figure 1 Building of the Water Corporation. Compositional analysis of proportioning and ratios.

Harmony has appeared in windows on the same facade due to the repetition of windows in the formed elements of the facade in accordance with fixed proportions. Note that the designer created the percentage of windows on the facade, which ranges from $17 \%$ to $21 \%$. 
Repetition of geometric elements of the facade, such as windows and balconies, Showing a distinct and unique element to break this repetition, as in the facade of the main entrance, a protruding entrance arch is formed to give importance and focus to the entrance. In terms of decor, the designer deliberately repeated some decorative geometric elements on the façade, such as a square with geometric patterns that adorn the façade and a repeating decorative element that adorns the façade's roof parapet. ("Figure 1") [9]

\section{CONCLUSION}

Architecture in Damascus during the French Mandate was influenced by European architecture in the nineteenth and twentieth centuries. The trends of European architecture were manifested mainly in the architecture of the compact residence areas of the French, in the architecture of large public buildings, as well as in the architecture of housing in the central part of the city.

Through the article and based on the documentary and analytical study of the construction development in the city of Damascus, the residential and public buildings that were built during the French Mandate in the city of Damascus were classified according to the adopted type of compositional solutions, where the features of the volumetric compositional organization and the architectural and artistic image of the development of Damascus during the French Mandate were determined, In addition to an analytical study of the building model.

The buildings under study were dominated by clear and regularly repeated proportions; symmetry was evident in most plans and facades, and the dominance of golden proportions and their repetition.

Generally, the compositional construction of the facades of western buildings was taken as a basis. Its use led to a high degree of transformation in architecture in Damascus.

\section{AUTHORS' CONTRIBUTIONS}

This paper is independently completed by Hiba Abass.

\section{REFERENCES}

[1] M. Dugman, Documentation and development of building materials for local residential an analytical applied study (a case of Damascene region). Damascus: Ph.D. thesis, department of architecture university of Damascus, 1999, pp.27-32.

[2] H. Abass, Architectural and decorative elements of Damascus public buildings during the period of the French Mandate, № 15. Moscow: Journal of Questions of the general history of architecture, 2020, pp.207-208.

[3] F. Frais, Damascus (1860-1946), the creation of the modern city. Paris: University of Paris VIII, 2004, pp.80-82.

[4] J.P. Garric, Architecture et théorie. L'héritage de la Renaissance, vol. 2. Paris: Publications de l'Institut national d'histoire de l'art, 2017, p.41.

[5] S. Chaouche, The impact of colonial urban planning on the factory of the Algerian city, № 37. Algeria: Journal of Sciences \& Technology, 2013, p. 43.

[6] S. Michael, The specificity and the role of the Arab architect in solving the problem of housing architecture (a comparative analytical study of models from the city of Damascus for traditional housing, during the French Mandate and after), vol. 20, № 2. Damascus: Damascus University Journal of Engineering Sciences, 2004, pp.250-253.

[7] N. Sehnawi, The Westernization of Daily Life in Beirut: 1860-1914, vol. 2. Paris: University Paris X, 1981, p.120.

[8] A. Kim, Features of the development of mansions of Chinese officials and merchants in Guangzhou in the first half of the 20th century, vol. 753, IOP Conference Series: Materials Science and Engineering, 2020, p. 6.

[9] R. Clark, Precedents in architecture analyticdiagrams, formative ideas, and partis, vol. 4. New Jersey: John Wiley \& sons, INC., 1999, pp. 282-283. 